\title{
NEURONAL RESPONSES OF THE RABBIT CEREBELLUM DURING ACQUISITION AND PERFORMANCE OF A CLASSICALLY CONDITIONED NICTITATING MEMBRANE-EYELID RESPONSE ${ }^{1}$
}

\author{
DAVID A. MCCORMICK ${ }^{2}$ AND RICHARD F. THOMPSON \\ Department of Psychology, Stanford University, Stanford, California 94305 \\ Received July 6, 1983; Revised June 5, 1984; Accepted June 6, 1984
}

\begin{abstract}
Neuronal activity was recorded from regions of the cerebellar cortex and dentate-interpositus nuclei during learning and/or performance of a classically conditioned nictitating membrane (NM - a third eyelid)/eyeblink response in the rabbit. It was found that neurons located within restricted portions of the ansiform lobule and anterior lobe cortical regions and of the dentate-interpositus nuclei respond in relation to the performance of the learned eyeblink response. Furthermore, chronic recordings from the dentate-interpositus nuclei revealed that these responses develop in close relation to the learning of the conditioned eyeblink response. Stimulation of the dentate-interpositus nuclei through the recording electrodes in some cases yielded eyelid closure and NM extension in both trained and untrained animals. Lesion of the axons of the dentate-interpositus nuclei (superior cerebellar peduncle), a manipulation which is known to abolish the learned eyeblink response, abolished the stimulation effect.

We have previously reported that lesions of the dentate-interpositus nuclei cause abolition of the learned eyeblink response. In the present study, we report that lesions of the regions of cerebellar cortex projecting to the dentate-interpositus nuclei do not permanently abolish the conditioned response, although the amplitudetime course of the learned response could be affected. These results, together with results of other studies, demonstrate that the medial dentate and/or lateral interpositus nuclei are active during learning and performance of the conditioned eyeblink response, are capable of producing this learned response, and are essential for the learning and retention of the conditioned eyeblink response. Therefore, the medial dentate and/or lateral interpositus nuclei are a part of the essential neuronal circuit involved in the learning and production of the classically conditioned eyeblink response in the rabbit.
\end{abstract}

Classical, or Pavlovian, conditioning is widely used to study the neuronal substrates of basic associative learning (Pavlov, 1927; Schniederman et al., 1969; Woody and Engel, 1972; Thompson et al., 1976; Kapp et al., 1979; Alkon, 1980; Cohen, 1980; Tsukahara et al., 1981; Kandel and Schwartz, 1982). Pavlov initially theorized that in mammals the association or connection between neuronal substrates representing a conditioned stimulus (e.g., tone, bell) and an unconditioned stimulus (e.g., leg shock, food powder) that produces a learned response resides within the cerebral cortex (Pavlov, 1927). However, numerous investigations have since reported that complete removal of the cerebral cortex does not abolish the ability of an animal to learn standard delay, classically conditioned so-

\footnotetext{
${ }^{1}$ We express our sincere gratitude to Carl Baier, Peggy Guyer, and Laura Mamounas for their contributions to these experiments, and to Dr. Eric Knudsen for helpful comments on the manuscript. This work was supported in part by National Science Foundation Grant BNS8106648, Office of Naval Research Contract N00014-83-K-0238, and National Institute of Mental Health Fellowship 1-F31-MH08673.

${ }^{2}$ To whom correspondence should be sent, at his present address: Department of Neurology Room C338, Stanford University Medical Center, Stanford University, Stanford CA 94305.
}

matic responses (Lebendinskaia and Rosenthal, 1935; Girden et al., 1936; Bromiley, 1948; Oakley and Russell, 1977; Norman et al., 1974). Indeed, it is now known that complete removal of all neural tissue above the level of the thalamus does not abolish the ability to learn the classically conditioned eyeblink response in the cat and rabbit (Norman et al., 1974; D. Enser, personal communication). These results imply that there must exist at or below the level of the thalamus some neuronal circuit which is capable of storing the basic association and executing the learned response. This subcortical association occurs in intact animals as well, since removal of the cerebral cortex after learning does not abolish the retention of the response (Oakley and Russell, 1977).

Recently, we have reported that the classically conditioned nictitating membrane (NM-a third eyelid)/eyeblink response of the rabbit is permanently abolished by removal of the ipsilateral, lateral cerebellar cortex, and dentate-interpositus nuclei (McCormick et al., 1981, 1982a), by lesions of the medial dentate and lateral interpositus nuclei alone (Clark et al., 1982, 1984), and by lesions of the superior cerebellar peduncle (Lavond et al., 1981; McCormick et al., 1982b). These lesions do not affect the animals' eyeblink response to an unconditioned stimulus (corneal airpuff), or the ability of the animal to learn the response rapidly with the NM-eyelid contralateral to the 
lesion. Furthermore, we have reported that lesions of the ipsilateral lateral cerebellum, if made before acquisition, prevent the animal from ever learning the NM-eyelid response on the side of the lesion (Lincoln et al., 1982). The cerebellum therefore may be a part of the subcortical neuronal circuit involved in the learning and production of the classically conditioned eyeblink response and, consequently, a putative site for learning-related neuronal plasticity to occur. Indeed, a number of authors have suggested that the cerebellum may be a site for the storage of motor learning, given its diverse afferent inputs, the organization of these afferents, its strong efferent connections with neuronal structures involved in motor control, and the regular and stereotypical organization of its cortical layers (Brindley, 1964; Marr, 1969; Albus, 1971; Gilbert, 1974; Eccles, 1977; Ito, 1982).

The present recording, stimulation, and lesion studies were done in an attempt to determine the role of the cerebellum in the production of classically conditioned responses and to define more closely which regions of the cerebellum are so involved. Portions of these results have been reported previously in brief (McCormick et al., 1981, 1982a; McCormick and Thompson, 1984).

\section{Materials and Methods}

Surgery. Sixty-seven male New Zealand White rabbits were used in the present study. Neuronal recordings were obtained by two methods: chronic implantation of recording electrodes in the dentate-interpositus (D-I) nuclei (32 rabbits) and acute recording electrodes positioned with a micromanipulator in the behaving animal ( 15 rabbits), as described previously (Berger and Thompson, 1978; McCormick et al., 1983). An additional 20 rabbits were subjected to aspiration of selected lobules of the cerebellar cortex after conditioning had taken place. All neuronal recordings were of unit clusters in which the action potentials of a few cells were substantially larger than the others (Fig. 1). The electrodes were stainless steel 00 insect pins coated with Epoxylite with a length of approximately $50 \mu \mathrm{m}$ of tip exposed.

Implantation of the two chronic recording electrodes and the manipulator base was done with the animal under halothane anesthesia ( 2 to $3 \%$ ) and with its head positioned such that the top of the skull at lambda was $1.5 \mathrm{~mm}$ lower than that at bregma. For the chronic recording study, the tips of the two recording electrodes were 1.0 to 2.0 $\mathrm{mm}$ apart in the medial-lateral plane. Electrodes were placed according to the following coordinates: 0.0 to $1.5 \mathrm{~mm}$ anterior to lambda, 2.0 to $6.0 \mathrm{~mm}$ lateral from the midline, and 12.5 to $14.5 \mathrm{~mm}$ below the surface of the skull at lambda.

To further assist in the proper positioning of the electrodes, unit activity was monitored as the electrodes were lowered. The deep cerebellar nuclei could be distinguished from the cerebellar cortex by the lack of cellular activity characteristic of the dense cell body layers of the cerebellar cortex. The electrodes were then secured to the skull with dental acrylic onto skull screws. A five-pin socket headstage, to which a headgear and wires to the amplifiers were attached later, was then secured to the animal's skull. A small loop of silk thread was sutured to the left NM to allow measurement of the movements of this third eyelid. The NM passively sweeps from nasal to temporal of the eyeball when the eyeball is retracted, a response which is controlled by the retractor bulbi muscle which is innervated by the abducens and accessory abducens nuclei (Cegavske et al., 1976; Gray et al., 1981; Marek et al., 1984). This extension occurs simultaneously with an effort to close the external eyelids (musculus orbicularis oculi) and a varying degree of contraction of the superficial facial musculature (McCormick et al., 1982c). Therefore, we use the term eyeblink response to indicate the extension of the NM across the eyeball and the attempted closure of the eyelids (the external eyelids are held open by the eyeclips; see below).

Restricted lesions of the ipsilateral cerebellar cortex were done in 20 animals by aspiration after acquisition of the conditioned eyeblink response. The brain cavity created by aspiration was lightly packed wth Gelfoam and the opening in the skull was replaced with bone wax. All 67 animals were allowed 5 to 7 days for recovery before behavioral training began or resumed.

Training procedure. After recovery from surgery, each animal was placed within a Plexiglas restrainer in a sound isolation chamber and allowed to adapt for $2 \mathrm{hr}$. Headgear containing the airpuff outlet nozzle, first stage field effect transistor amplifiers (Brakel et al., 1971), and a minitorque potentiometer were attached to the animal's headstage during adaptation and behavioral training. The left eyelids were held open by eyeclips and the movement of the NM was monitored through the use of a minitorque potentiometer, by attaching a thread from the wire wiper arm of the potentiometer to the suture in the animal's NM.

Throughout training the conditioned stimulus (CS) was a $350-\mathrm{msec}$, $1-\mathrm{kIIz}$ tone at $85 \mathrm{db}$ SPL, and the unconditioned stimulus (UCS) was a 100 -msec airpuff directed at the cornea measuring $2.1 \mathrm{Newton} / \mathrm{cm}^{2}$ ( 3 psi) at the source. The interval from the onset of the tone to the onset of the airpuff (interstimulus interval) was set at $250 \mathrm{msec}$. The $250 \mathrm{msec}$ prior to the onset of the CS is referred to as the pre-CS period and was used to measure spontaneous activity. The 250 msec after the onset of the CS and before the onset of the UCS is referred to as the CS period, whereas the $250 \mathrm{msec}$ after the onset of the UCS is referred to as the UCS period.

Before acquisition of the conditioned response, 16 of the animals with chronic electrodes implanted within the deep cerebellar nuclei were given one session of explicitly unpaired training consisting of 104 tone-alone trials and 104 airpuff-alone trials, pseudorandomly intermixed. The eyeblink response was then conditioned in daily sessions of 13 blocks, each block consisting of one tone-alone trial followed by eight paired trials, for a total of 117 trials/day. The intertrial interval for all training was pseudorandom and ranged from 20 to $40 \mathrm{sec}$ with a mean value of $30 \mathrm{sec}$. A conditioned response was defined as movement of the NM $0.5 \mathrm{~mm}$ or greater within the interstimulus interval. The animals were said to have reached criterion performance upon exhibiting eight conditioned responses on any nine consecutive trials. All animals were trained one additional day after this criterion was met. Animals for the acute recordings were trained one more day for neuronal data collection.

Data collection and analysis. For the recording studies, the unit activity was stored on magnetic tape along with movements of the NM and synchronizing pulses denoting the onset of the trial as well as the onset of the CS and the UCS. For the acute recordings, a micromanipulator carrying four microelectrodes at the corners of a rectangular array $2 \mathrm{~mm} \times 3 \mathrm{~mm}$ was used (McCormick et al., 1983). The acute recording electrodes were lowered in 0.5 - to $1.0-\mathrm{mm}$ increments. After each increment, the neuronal activity was recorded for one block (nine trials) of training trials. The recorded data were analyzed off-line on a PDP 11/03 minicomputer using pulse height level discriminators to detect only the larger amplitude action potentials.

Neuronal responses were summarized as a peristimulus histogram for each block of training trials. For the acute recordings, photographs were taken of each histogram and were matched with the appropriate recording site as determined through histology. For the chronic recording data, peristimulus histograms were also summarized for the total of each day of training. If a recording site contained a response within the CS period, the latency to onset of this response and the corresponding NM response was measured directly off of the computer screen for each trial. The onset of the behavioral NM response was defined as the point at which the NM trace first deviated from the base line and was continuous with the larger response. Similarly, the onset of neuronal responses was defined as the first histogram bar which was above the background firing rate and continuous with the larger response. This method gave an accuracy of onset latency measurement of approximately $3 \mathrm{msec}$ for the NM response and $10 \mathrm{msec}$ for the unit response. Occasionally, onset latencies were not measurable, particularly for smaller responses. In these cases, the onset latency was neither measured nor estimated.

For the acute studies, covariance of unit onset latency with NM onset latency was measured for the nine training trials for each recording site in an effort to help determine which neuronal responses were most related to performance of the eyeblink conditioned response. This measure of covariance is possible since, in well trained animals, the onset latency of the NM response varies in the range of 100 to 250 msec after the onset of the tone.

The neuronal responses within the $\mathrm{CS}$ period were grouped into three classifications: those which covaried significantly $(r \geq 0.67)$ with the onset latency of the NM behavioral response; those which did not covary significantly; and those which did not covary significantly and had onset latencies within 50 msec after the onset of the tone (see Figs. 2 and 3). The first classification is thought to represent responses which are in some way related to the performance of the conditioned eyeblink response, whereas the responses of the last classification are 
more related to the occurrence of the tone than to the occurrence of the behavioral response.

The chronic recording data were further analyzed according to the amplitude of the response by the standard scores method, as described previously (Berger and Thompson, 1978). Each 250-msec period (preCS, CS, UCS) of each trial was further divided into 125 -msec halves. This was done since most neuronal responses within the CS period which related to the occurrence of the conditioned response occurred within the second half of this period (see Fig. 5). Mean number of action potentials counted was computed for each $125-\mathrm{msec}$ period. As a measure of variation of the spontaneous firing rate, a grand mean and standard deviation were computed for counts in the pre-CS periods across each training session. Standard scores were then computed according to the following equation:

$$
\left(\overline{\mathrm{CS}}_{\text {half-block }}-\overline{\text { PreCS }}_{\text {half-block}} /\left(\mathrm{SD} \text { PreCs } \mathrm{Session}_{\text {sion }}\right)\right.
$$

Figure 7 relates such a measure of late CS unit activity with the increase of the conditioned response as measured in millimeter. milliseconds. This figure is based on 7 of the 10 animals whose recording sites revealed robust increases in neuronal activity during learning of the response. The other 3 animals were trained on a different paradigm for another study (Mamounas et al., 1983).

Stimulation and histology. Each recording site was marked by passing direct current (DC) of $100 \mu \mathrm{A}$ for 3 sec. This current deposits iron particles from the stainless steel electrode tip which can later be stained with potassium ferrocyanide. In a few of the animals it was noticed that the onset of this stimulation produced discrete ipsilateral eyeblinks. Therefore, to study this phenomenon further, succeeding animals were stimulated after completion of behavioral training with a 60 $\mathrm{Hz} \mathrm{AC}$ stimulus of $150 \mathrm{msec}$ in duration and ranging from 10 to 300 $\mu \mathrm{A}$. The behavioral responses of the animals varied from no observable response to postural adjustments, head movements, eye movements, movements of the vibrissae, movements of the forelimbs or hindlimbs, ear movements, and eyelid closure along with NM extension (Fig. 9). Eyelid closure-NM extension was elicited in isolation from other movements in a number of instances, whereas in other instances other bodily movements were elicited in conjunction with the eyelid closure (e.g., head turning, postural adjustments). It was noticed that most behavioral responses had an intensity threshold of approximately $30 \mu \mathrm{A}$, with 30 to $100 \mu \mathrm{A}$ eliciting larger movements but still of a relatively specific nature. Stimulation at higher intensities $(>200 \mu \mathrm{A})$ were found to give rise to movements involving a large number of muscles (e.g., forelimbhindlimb movements, postural adjustments, head turning, eye movements, facial movements, and so on) if the electrodes were localized within the deep cerebellar nuclei. Therefore, a criterion for whether or not a recording site elicited an eyeblink was set at $100 \mu \mathrm{A} \mathrm{AC}$ or the onset of the $100 \mu \mathrm{A}$ of direct current. This criterion is meant to indicate whether the general region of the recording site contained neural elements which when activated could elicit eyelid closure and NM extension.

During stimulation, movements of the external eyelids were measured in the same manner as the movements of the NM: by connecting the minitorque potentiometer to a suture in the upper eyelid.

All animals were sacrificed with an overdose of sodium pentobarbital (Nembutal) and perfused through the heart with $10 \%$ formalin. Their brains were removed, embedded in albumin, and sectioned at $80 \mu \mathrm{m}$ on a freezing microtome. The sections were stained with cresyl violet for cell bodies and potassium ferrocyanide for the marking lesions. For the acute recordings, a reconstruction of the recording sites was made on photomicrographs of the actual electrode path (McCormick et al., 1983).

\section{Results}

The conditioned NM-eyelid response with corneal airpuff training of one eye involves a coordinated retraction of the eyeball, resulting in a largely passive extension of the NM (a cartilaginous third eyelid), together with closure, or attempted closure, of the external eyelids (the eyeclips hold these eyelids open), and a variable degree of contraction of the facial musculature, including in some animals not only the periocular musculature but also the nasal musculature involved in movements of the vibrissae and respiration. The contralateral eye typically develops the same responses, but they are smaller in amplitude and have greater interanimal variability. However, over the course of training, all of the components of the conditioned responses of both eyes show virtually perfect correlation, both in terms of amplitude and latency to onset (McCormick et al., 1982c).

The primary neurons responsible for the retraction of the eyeball appear to be located within the abducens and accessory abducens nuclei and innervate the retractor bulbi muscle of the eye (Cegavske et al., 1976; Gray et al., 1981; Marek et al., 1984). The eyelid musculature (musculus orbicularis oculi) is innervated by the seventh (facial) nucleus (Courville, 1966a; Brodal, 1981). During performance of the conditioned response, the onset latency of the EMG activity of the orbicularis oculi is the shortest, occurring on the average $29.5( \pm 8.2) \mathrm{msec}$ before the onset of the NM extension. In a well trained animal, NM extension has an average minimum onset latency of about 100 msec and the eyelid EMG averages about $70 \mathrm{msec}$ after the onset of the tone (McCormick et al., 1982c). In the present study, we measured only the NM extension response; however, we use the term "eyeblink response" to refer to the NM extension and effort to close the external eyelids.

Acute mapping. Neuronal recordings from 323 sites were obtained from throughout the lateral cerebellar cortex and deep nuclei with 91 of the recordings coming from the ansiform lobule (Figs. 1 to 3 ). Of the 323 recordings, 90 (28\%) were found to respond in the CS period. These responses were located within the ansiform lobule, the anterior lobe, the D-I nuclei, and portions of the midline (vermal) cortex. Twenty-nine (32\%) of the responses within the CS period correlated significantly with the onset of the eyeblink response $(r \geq 0.67, d f=7)$. A number (22) of such responses were found within the 91 recording sites located in the ansiform cortex above the D-I nuclei (Fig. 2). The significant correlations from this region ranged from 0.76 to as high as 0.98 , with a mean value of 0.88 . The relatively high values of many of these correlations indicate that these responses were highly related to the performance of the learned eyeblink response (see Figs. 1 and 2). The mean onset latency for these neuronal responses was $29.3 \pm 16.5$ msec before the onset of the NM response and ranged from 5 to $59 \mathrm{msec}$ before the onset of the NM response.

Four of the $14(29 \%)$ acute recording sites within the medial dentate and lateral interpositus nuclei also revealed similar responses (see Fig. 2 and chronic recording data in Figs. 5, 6, and 8).

The neuronal responses found within the midline folia did not correlate significantly with the onset of the NM behavior (Fig. 3). The responses in the more posterior folia tended to occur at a relatively short latency after the onset of the tone ( $<50 \mathrm{msec}$ ) and did not covary with the onset of the NM response. Such results indicate that this activity was probably more related to the onset of the tone rather than to the onset of the NM behavioral response and therefore was labeled "T" type responses (Fig. 3). This region of the cerebellar cortex is known to receive an auditory projection (Snider and Stowell, 1944; Fadiga and Pupilli, 1964). A few T responses were also found scattered through out the ansiform cortex (Fig. 2). Interestingly, neuronal responses obtained from a number of chronic sites within the D-I nuclei also possessed similar characteristics (see below).

The neuronal responses found within the posterior sections of the anterior lobe (level -1.0, Fig. 3) did not significantly covary with the NM behavior nor did they occur with a short enough latency after the onset of the tone to be labeled $T$ responses. Some of these neurons appeared to fire in phase with the animal's respiration. Since it is known that in the present training paradigm some animals develop a conditioned increase in movements of the nasal musculature involved in respiration (McCormick et al., 1982c), the neuronal responses of this region may represent proprioceptive or somatosensory feedback from the muscles and skin surfaces (e.g., nasal region and vibrissae). In summary, the acute recording data indicate 

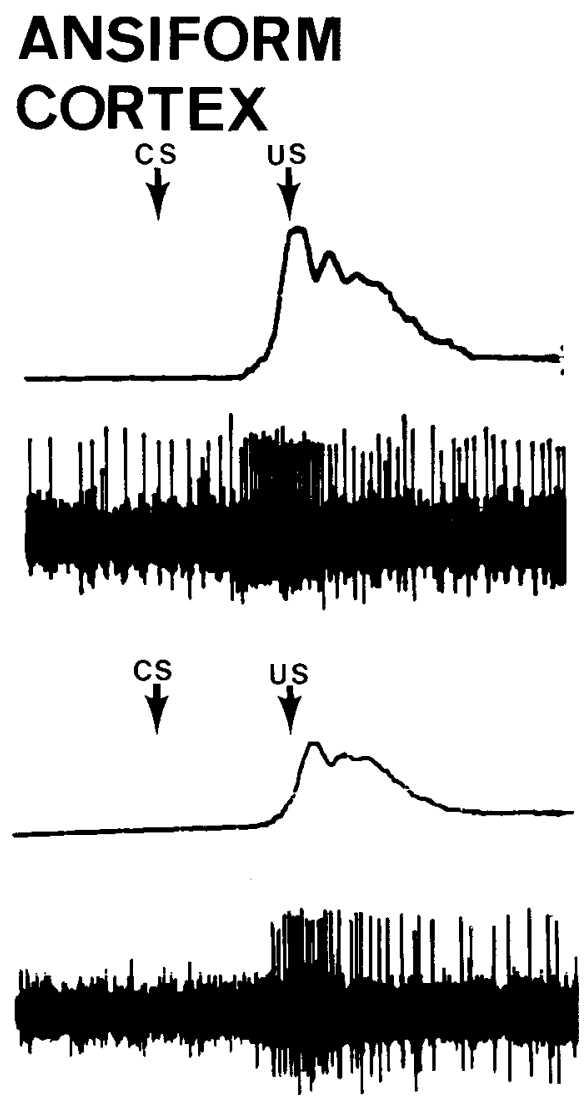

\section{MEDIAL DENTATE}
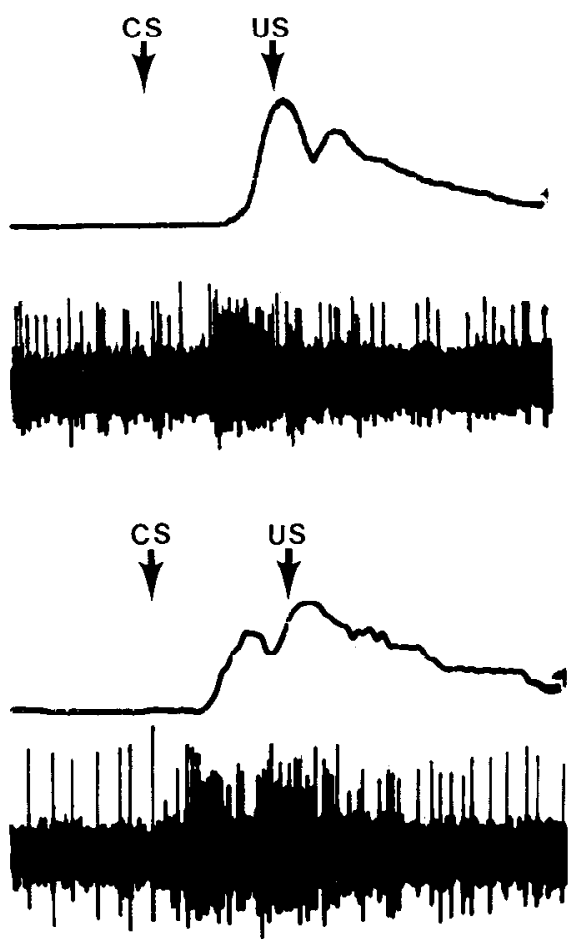

Figure 1. Examples of multiple unit activity ("unit clusters") from the ansiform cortex and the medial dentate-lateral interpositus nuclear region during performance of learned NM extension and eyelid closure response. The top trace of each record represents the movements of the NM with up being extension across the eyeball. The lower traces are the unit activity recorded from one training trial. Arrows indicate the onset of the CS (tone) and the US (corneal airpuff). Each trace is $1 \mathrm{sec}$ in length.

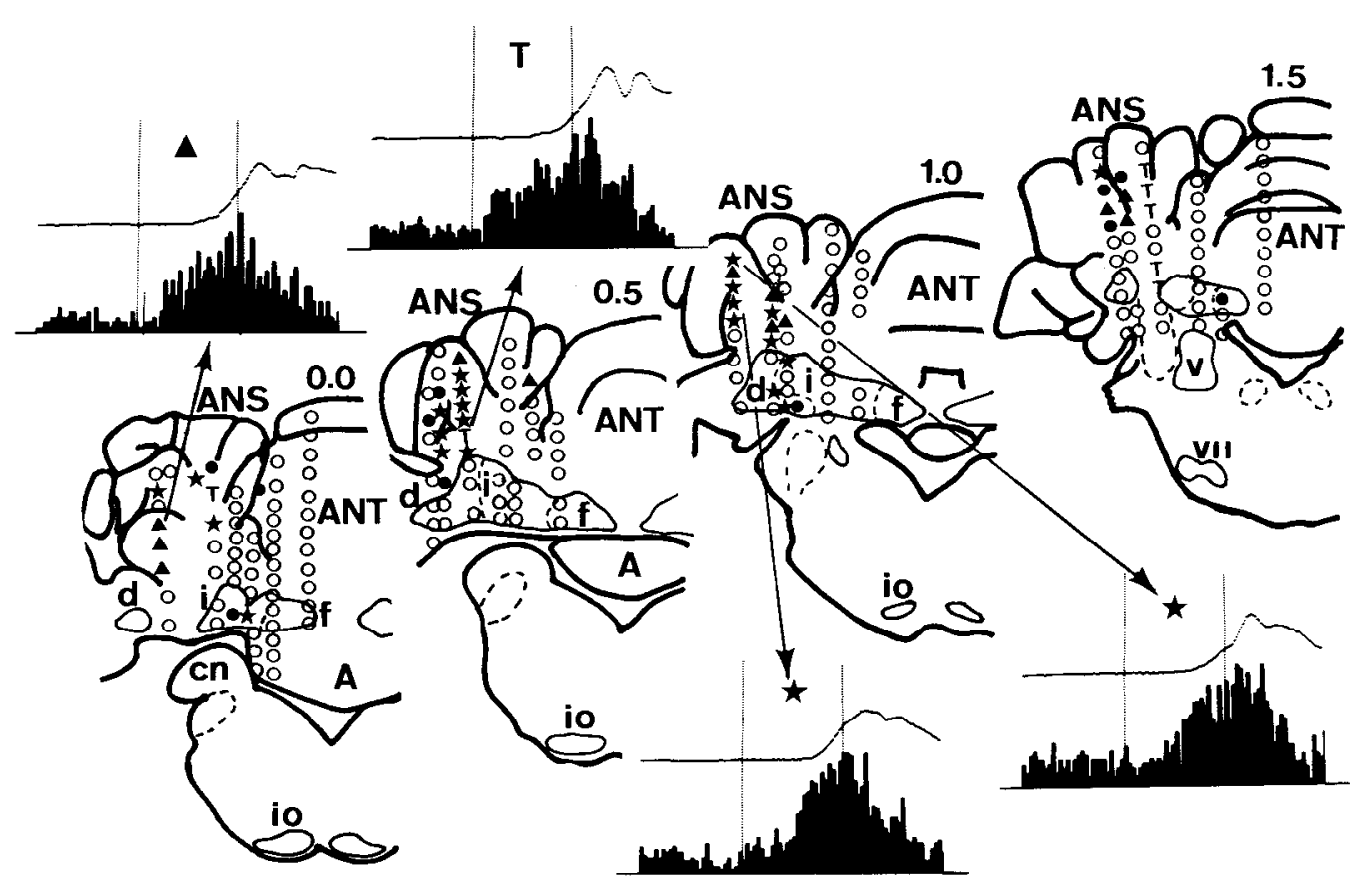

Figure 2. Neuronal responses of the anterior sections of the cerebellar cortex during performance of the conditioned eyeblink response. A star indicates a recording site in which the onset of the unit activity significantly covaried ( $r \geq 0.67$ ) with the onset of the behavioral NM response. Triangles indicate neuronal responses which did not significantly correlate with the onset of the conditioned response. $T$ indicates a recording site in which the onset of the neuronal response did not covary with the NM response and was less than $50 \mathrm{msec}$ after the onset of the tone. Within the peristimulus histograms, the upper trace represents the movements of the NM with up being extension across the eye. The first vertical line represents the onset of the tone, and the second vertical line represents the onset of the corneal airpuff. Each histogram bar is 9 msec in duration and each trace is a total of $750 \mathrm{msec}$ in duration. $A$, lobule a; $A N S$, ansiform lobule (crus I and crus II); $A N T$, anterior lobe; $c n$, cochlear nucleus; $d$, dentate nucleus; $f$, fastigial nucleus; $i$, interpositus nucleus; $i o$, inferior olive; $v$, vestibular nuclei; vii, seventh (facial) nucleus. 
Figure 3. Neuronal responses of the posterior sections of the cerebellar cortex during performance of the learned eyeblink response. See the legend to Figure 2 for explanation of figure and symbols. $A N T$, anterior lobe; $B$, lobule $\mathrm{b} ; C$, lobule $\mathrm{c}$; $i$, inferior olive; $P M$, paramedian lobule.

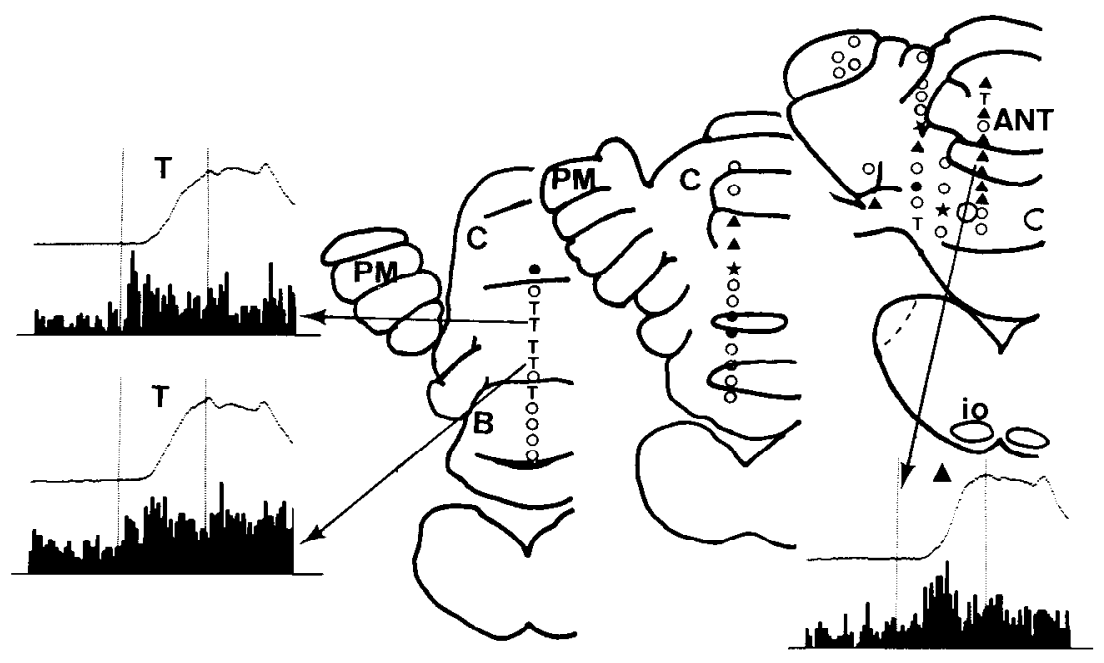

that restricted regions of the cerebellar cortex, particularly the folia of the ansiform lobule, possess neuronal responses during training which are significantly related to the performance of the conditioned response.

Chronic recordings. Chronic recordings were obtained from 54 sites in the deep cerebellar nuclei in 32 animals over the course of learning. Of the 54 chronic recordings, $22(41 \%)$ were found to exhibit T-type responses at some point during behavioral training. The majority (16 of 22 ) of these responses were relatively weak and apparent only in average histograms from a number of trials. The average onset latency of these responses was $12.0 \mathrm{msec}( \pm 3.7 \mathrm{msec})$, which agrees with earlier reports of response latencies of neurons within the D-I nuclei to intense auditory stimulation in the monkey (Mortimer, 1973, 1975). The majority of these $\mathrm{T}$ responses were present throughout behavioral conditioning. A small number of the responses either significantly increased in amplitude (4 of 22) or decreased in amplitude ( 4 of 22 ) during behavioral conditioning.

Responses to the onset of the airpuff were found at $42(78 \%)$ of the 54 recording sites at some point during behavioral conditioning. Again, the large majority of these responses to the onset of the airpuff were present both before and after the learning of the behavioral response. A small number significantly decreased ( 6 of 42 ) and no responses significantly increased in amplitude during behavioral training. The average onset latency of these responses to the airpuff was $4.6 \pm 1.9$ msec. The possibility that these responses possessed significant auditory components (the airpuff escaping from the outlet nozzle generates a broad band noisy stimulus) was tested in 13 of the animals by misdirecting the airpuff to above the animal's head for the first block of unpaired trials. Of the 24 recording sites in these animals, the neurons of 18 responded to the airpuff. Misdirection of the airpuff away from the cornea to a point of equal distance from the animal's ears was found to abolish or significantly reduce the neuronal response in $9(50 \%)$ of these cases (Fig. 4). Therefore, the neuronal response of some regions of the D-I nuclei is related to the somatosensory components of the airpuff and/or performance of the unconditioned response. The fact that the onset latencies of these responses $(4.6 \mathrm{msec})$ is shorter than the earliest eyelid EMG (musculus obicularis oculi) responses to the airpuff $(7.5 \mathrm{msec}$, McCormick et al., 1982c) would rule out feedback from the movement as a cause for the initial portions of these responses. The fact that misdirection of the airpuff did not abolish the neuronal response to the airpuff in the other 9 cases indicates that these responses were auditory in nature. Therefore, without such a test, similar responses can only be interpreted with caution. A number (7) of recording sites responded to the

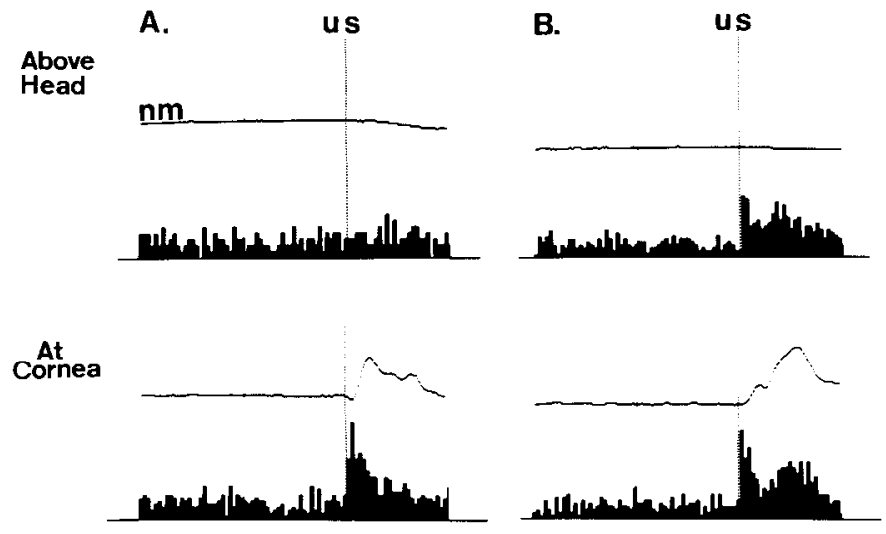

Figure 4. Effect of misdirecting the airpuff away from the cornea on the responses of the neurons of the D-I nuclei to this stimulus. $A$ illustrates an example in which the response to the airpuff was dependent upon direction of the airpuff at the animal's cornea, therefore implying that this response is related to somatosensory inputs and/or performance of the unconditioned eyeblink response. $B$ illustrates a case in which the misdirection of the airpuff did not significantly alter the neuronal response, thereby implying that these neurons are responding to the auditory components of the airpuff. The airpuff is a broad band noisy stimulus generated by escape of the air from the outlet nozzle. Note the sharp onset and short latencies of both responses. This is typical of the neuronal responses to both the tone and the airpuff.

auditory components of the airpuff without giving a noticeable response to the tone $\mathrm{CS}$ indicating that a broad band noisy stimulus may be a more effective auditory stimulus than a pure tone for eliciting responses from the neurons of the deep cerebellar nuclei.

Of the 54 chronic recording sites in the deep cerebellar nuclei, $20(37 \%)$ developed a neuronal response in the CS period as the animal learned the behavioral response (see Figs. 5 to 8 ). These responses were divided into two classifications, those which possessed a standard score (see "Materials and Methods") of greater than 2.0 on the postcriterion day of training and those which did not. The responses which were greater than 2.0 standard scores will hereafter be referred to as the stronger responses and those which did not will be referred to as the weaker responses. The weaker type responses were only evident within cumulative histograms of neuronal responses over a number of trials. Of the 54 responses, $10(19 \%)$ were of the stronger type and $10(19 \%)$ were of the weaker type. The locations of the recording sites which developed a neuronal 

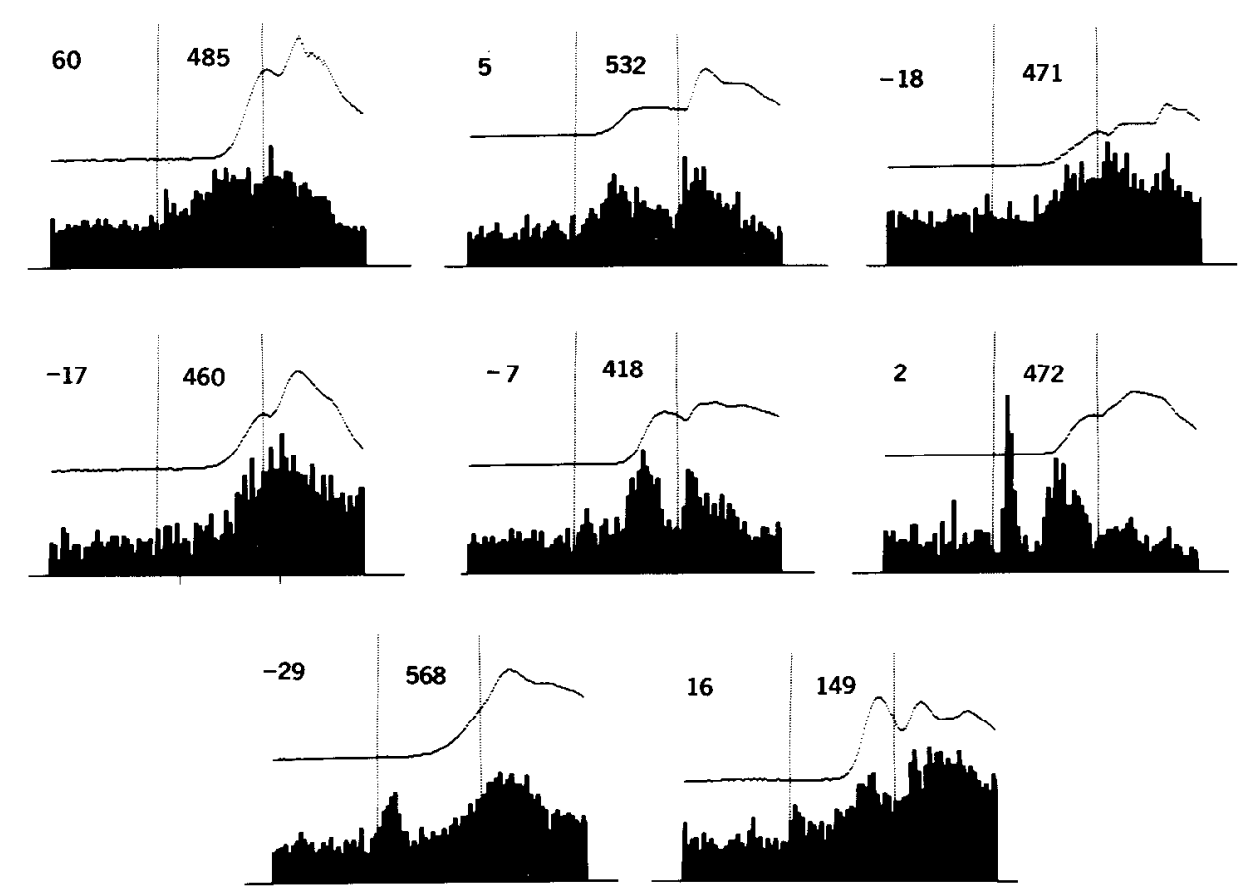

Figure 5. Examples of neuronal responses within the D-I nuclei during performance of the learned eyeblink response. Each histogram is $750 \mathrm{msec}$ in duration and is an average of all paired trials on the day of overtraining, with each histogram bar being $9 \mathrm{msec}$ in duration. The first vertical line represents the tone onset and the second vertical line represents the onset of the corneal airpuff. The number above each histogram corresponds to the animal's identification number. The average difference in onset latency between the neuronal responses and the NM behavioral response is indicated in the upper left corner of each histogram, with positive latencies indicating neuronal responses which occurred before the NM response.

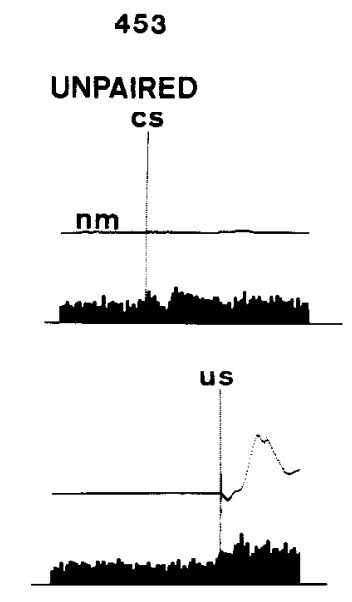

PAIRED
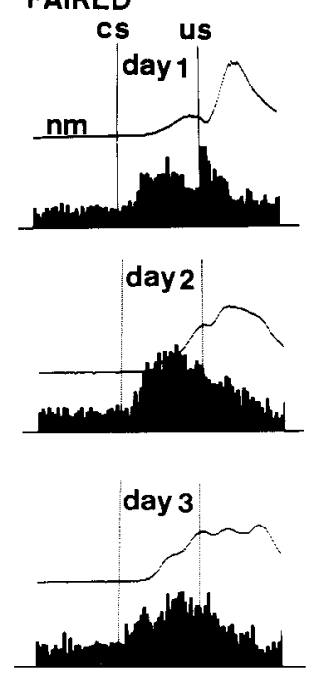

Figure 6. Example of the most inpressive change in neuronal unit activity within the medial dentate-lateral interpositus nuclei during unpaired and paired presentations of the training stimuli. The animal was first given pseudorandomly unpaired presentations of the tone and corneal airpuff, in which the neurons responded very little to either stimulus. However, when the stimuli were paired together in time, the cells began responding within the CS period as the animal learned the eyeblink response. The onset of this unit activity preceded the behavioral NM response within a trial by 36 to $58 \mathrm{msec}$. Stimulation through this recording site yielded ipsilateral eyelid closure and NM extension. Each histogram bar is $9 \mathrm{msec}$ in duration. The upper trace of each histogram represents the movements of the NM with up being extension across the eyeball. response of the stronger type are represented in Figure 8, along with the recording sites which did not develop any response within the CS period. The stronger responses were found mainly within the medial dentate and lateral interpositus nuclear regions.

Figure 7 illustrates the increase of unit activity within the second half of the CS period over the course of learning in comparison to the amplitude of the conditioned response, averaged over seven animals. Note that the neuronal responses of the D-I nuclei increase in close relation to the increase in the size of the conditioned response $(r=0.90)$. Figure 5 presents representative neuronal responses obtained from the D-I nuclei. These responses reveal that the temporal firing pattern of the neurons in different recording sites can differ significantly, with five sites responding both to the tone and during the conditioned response, and nine responding during performance of both the conditioned response and the unconditioned response. The onset latencies of these neuronal responses were found to differ markedly between recording sites, from consistently occurring before the NM response by 40 to $60 \mathrm{msec}$ (animals 453 and 485 , Figs. 5 and 6 ) to occurring after the onset of the NM response by up to $29 \mathrm{msec}$ (animal 568, Fig. 5). The overall mean onset latency was $5.8 \mathrm{msec}$ before the conditioned $\mathrm{NM}$ response $( \pm 30.3 \mathrm{msec})$. Of particular interest is the response pattern illustrated in Figure 6. These neurons did not respond to the CS and responded only weakly to the UCS when the animal was given unpaired training before learning. However, when the animal was shifted to paired conditioning, a robust neuronal response within the CS period developed as the animal learned the behavioral eyeblink response. This response developed further over subsequent days (days 2 and 3 of acquisition) and came to yield standard scores (see "Mate- 


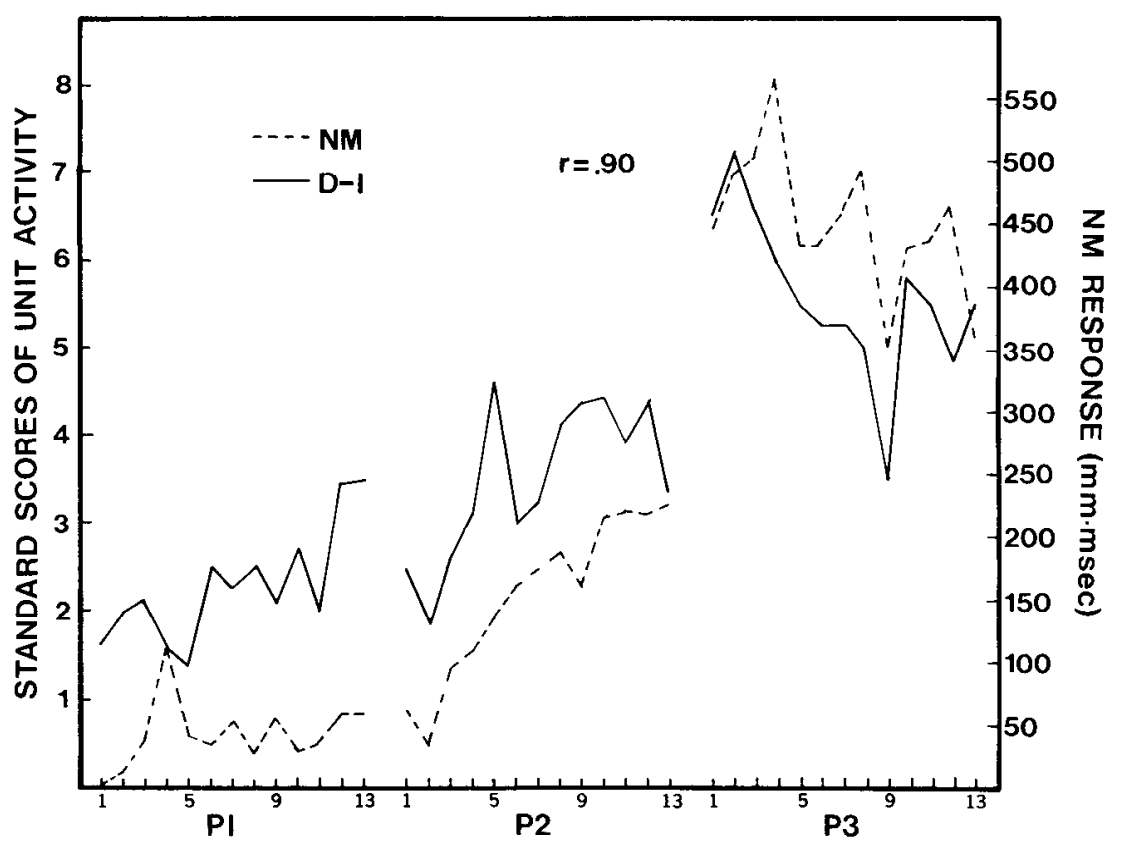

TRAINING DAY AND BLOCK

Figure 7. Amplitude of the conditioned response in comparison to the magnitude of the D-I neuronal activity in the second half of the CS period over the course of learning. Standard scores were calculated by finding the mean number of action potentials counted for the block of training trials in question, subtracting the number of counts in the corresponding half of the pre-CS period for that block, and dividing by the standard deviation over the entire training session:

$$
\left(\overline{\mathrm{CS}}_{\text {half-block }}-\overline{\mathrm{PCS}}_{\text {half-block }}\right) /\left(\mathrm{SD} \mathrm{PCS}_{\text {session }}\right)
$$

The magnitude of the conditioned response was measured as the area under the curve described by the amplitude-time course of the NM response in millimeter $\cdot$ milliseconds.

rials and Methods") as high as 12.5. Furthermore, this response preceded the NM response by approximately 38 to $56 \mathrm{msec}$ throughout the acquisition of the learned response (Fig. 6). The recording site for this electrode was on the border between the dentate and interpositus nuclei at approximately A-P 0.5 (see Fig. 8). Stimulation through this recording site produced an eyeblink response. A similar response pattern was observed in one other animal (animal 485, Fig. 5) in which the recording site was similar to that of Figure 8, although in this animal the neurons responded well to the airpuff before behavioral training began.

Stimulation. Of the 54 recording sites in the D-I nuclei, 24 were tested by microstimulation through the recording electrode after behavioral training had ended. Of these 24 sites, stimulation caused an eyeblink response to be performed in 14 (58\%) of them (Fig. 9).

When eyelid closure-NM extension was the lowest threshold response, increasing the stimulus intensity increased the amount of facial musculature involved in the contraction more often than recruiting muscles not related to facial movements (e.g., hindlimb movements). Measurement of the onset latency in three animals yielded an estimate of $32.2 \pm 5.0 \mathrm{msec}$ for NM and $34.0 \pm 5.5 \mathrm{msec}$ for the eyelids. The movements of the external eyelids were measured in the same manner as the movements of the NM, by attaching the wire wiper arm of the potentiometer to a loop of suture thread in the eyelid (see "Materials and Methods").

The spatial distribution of these stimulation sites, along with ineffective sites, is illustrated in Figure 8 . Note that the effective stimulation sites are distributed within the medial dentate and interpositus nuclei corresponding well to the sites which developed neuronal responses during learning of the behavioral response. Indeed, of the 20 recording sites which developed neuronal activity related to the performance of the learned response, 8 of 9 tested by stimulation yielded eyeblink responses, implying that regions of the deep cerebellar nuclei which develop neuronal responses related to the performance of the learned response contain neural elements which when activated can cause the response. The reverse implication, that sites which yield eyeblinks when stimulated will develop neuronal responses is true in a smaller but still significant proportion of cases ( 9 of $14 ; 64 \%$ ). This lower percentage may have its basis in a difference in the neuronal populations stimulated and those which were recorded from, especially since stimulation can activate both axons and cell bodies, and chronic recordings from our type of electrodes are largely from cell bodies. Indeed, the stimulation point at which eyeblinks were elicited with the lowest threshold $(10 \mu \mathrm{A})$ was from a recording site at the top of the fibers just beneath the interpositus nucleus (see Fig. 8). Neuronal responses within the CS period did not develop at this recording site during learning of the eyeblink response.

None of the nine recording sites which did not yield eyeblinks when stimulated developed neuronal responses related to performance of the conditioned response.

D-I stimulation in five untrained animals also yielded eyeblinks, therefore implying that the neuronal circuitry from the deep cerebellar nuclei to the motoneurons controlling eyeblinks (abducens, accessory abducens, facial nuclei) is not dependent upon the learning of this response. However, it is not yet known whether the threshold for stimulation-induced eyeblinks changes as the animal learns the response. 

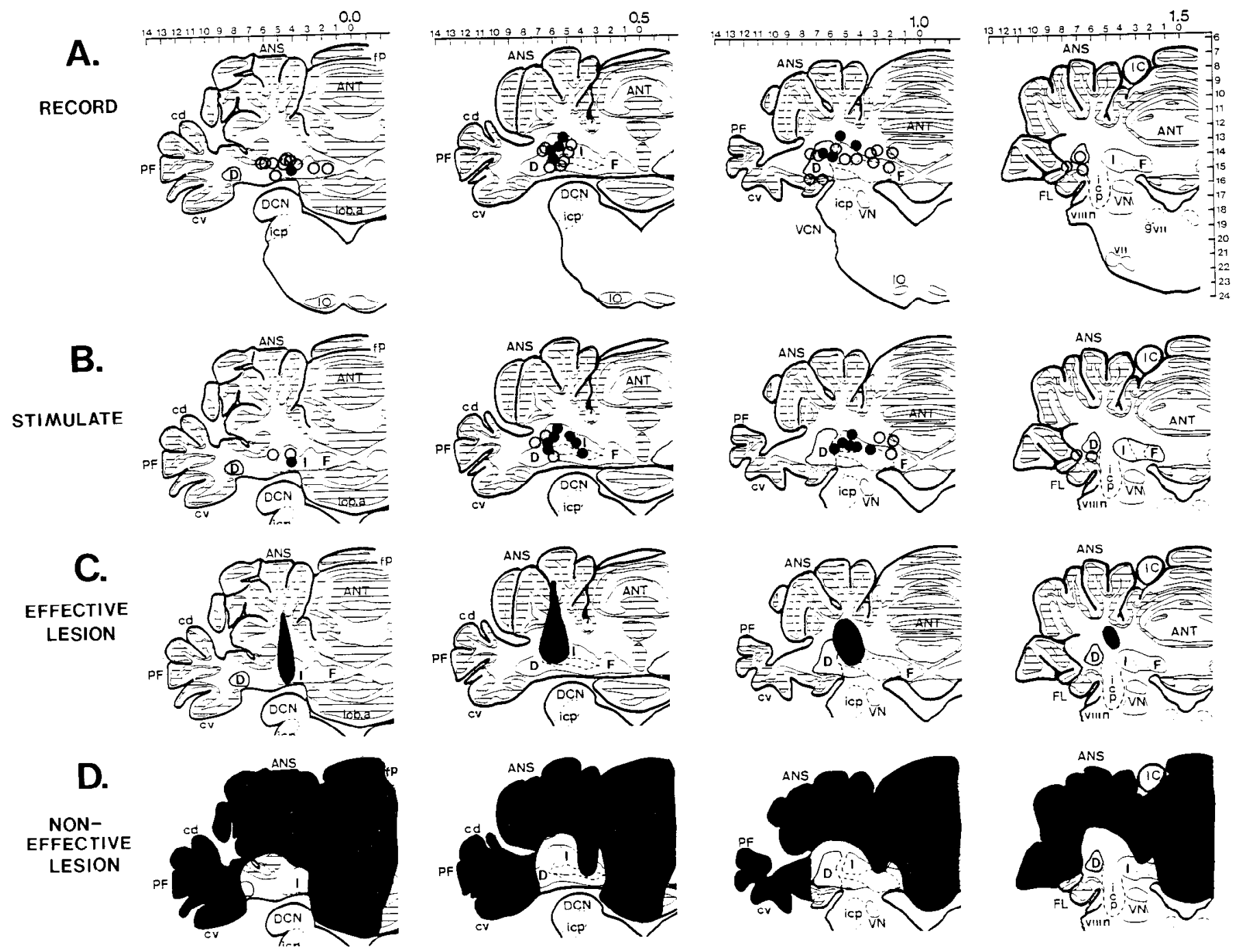

Figure 8. Summary diagram of the chronic recordings, stimulation, D-I lesions, and incffective lesions of the ccrebellar cortex. $A$ illustrates the recording sites (-) that developed neuronal responses within the CS period which were greater than 2.0 standard scores, as well as the recording sites $(O)$ which did not develop a neuronal response within the CS period. $B$ illustrates the sites at which $60 \mathrm{~Hz}$ stimulation of $100 \mu \mathrm{A}$ or the onset of direct current stimulation of $100 \mu \mathrm{A}$ produced ipsilateral NM extension and eyelid closure. The sites which were ineffective in eliciting eyeblink responses are represented by open circles. $C$ illustrates a typical stereotaxic lesion of the medial dentate-lateral interpositus nuclear region which abolished the conditioned response (Clark et al., 1984). $D$ illustrates a composite drawing of aspirations of three animals which were ineffective in abolishing the learned eyeblink response. Note that the medial dentate-lateral interpositus region not only develops neuronal responses related to the performance of the learned response during training (see Figs. 1, 5, and 6) but, when stimulated, will elicit eyeblink responses which are dependent, as is the learned response, on the intactness of the superior cerebellar peduncle. Furthermore, lesioning of this region of the deep cerebellar nuclei permanently abolishes the learned response, whereas cortical lesions which circumscribe this region do not. The large numbers above each section indicate the number of millimeters anterior to the lambda bone suture, and the dorsal-ventral numbers indicate the number of millimeters ventral to the surface of the skull at the lambda-sagittal suture intersection. ANS, ansiform lobule (crus I and crus II); $A N T$, anterior lobe; $c d$, dorsal crus; $c v$, ventral crus; $D$, dentate nucleus; $D C N$, dorsal cochlear nucleus; $F$, fastigial nucleus; $F L$, flocculus; $f p$, primary fissue; $I$, interpositus nucleus; $I C$, inferior colliculus; $i c p$, inferior cerebellar peduncle; $I O$, inferior olive; $l o b$. $A$, lobule A (nodulus); PF, paraflocculus; VCN, ventral cochlear nucleus; vii, seventh nucleus; viii $n$, nerve of the eighth nucleus; VN, vestibular nucleus.

It has been reported previously that transection of the brainstem at the point where the superior cerebellar peduncle leaves the cerebellum to enter the brainstem abolishes the ability of stimulation of the D-I nuclei to elicit body movements (Schultz et al., 1979). Similarly, we found in two animals that electrolytic lesion of the superior cerebellar peduncle abolished the ability of D-I stimulation to elicit eyeblinks at even 4 times prelesion threshold level.

Lesions of cerebellar cortex. Removal of restricted regions of the cerebellar cortex did not abolish the learned response in 18 of 20 animals tested, with the following regions being removed: ansiform lobule (crus I and crus II, $n=7$ ); lobulus simplex (Hemispherical VI, $n=7)$; paramedian lobule $(n=6)$; para- flocculus ( $n=3)$; vermal regions-lobule a, nodulus ( $n=1)$; lobule $\mathrm{b}$, uvula $(n=1)$; lobule $\mathrm{c}$, medius medianus and pyramis $(n=5)$; and the anterior lobe $(n=5)$ (Brodal, 1940). Examples of the cortical lesions and conditioned eyeblink responses are presented in Figure 10. These ineffective lesions not only include all of the cerebellar cortex (except for the flocculus), but also include the fastigial nuclei and the lateral dentate nucleus.

Of the two animals in which the conditioned response was abolished by cerebellar cortical lesion, one had removal of the ansiform-paramedian lobules and the paraflocculus ( $\mathbf{M c}$ Cormick et al., 1982a) and the other had removal of the dorsal half of the vermal lobes. However, removal of the ansiform- 


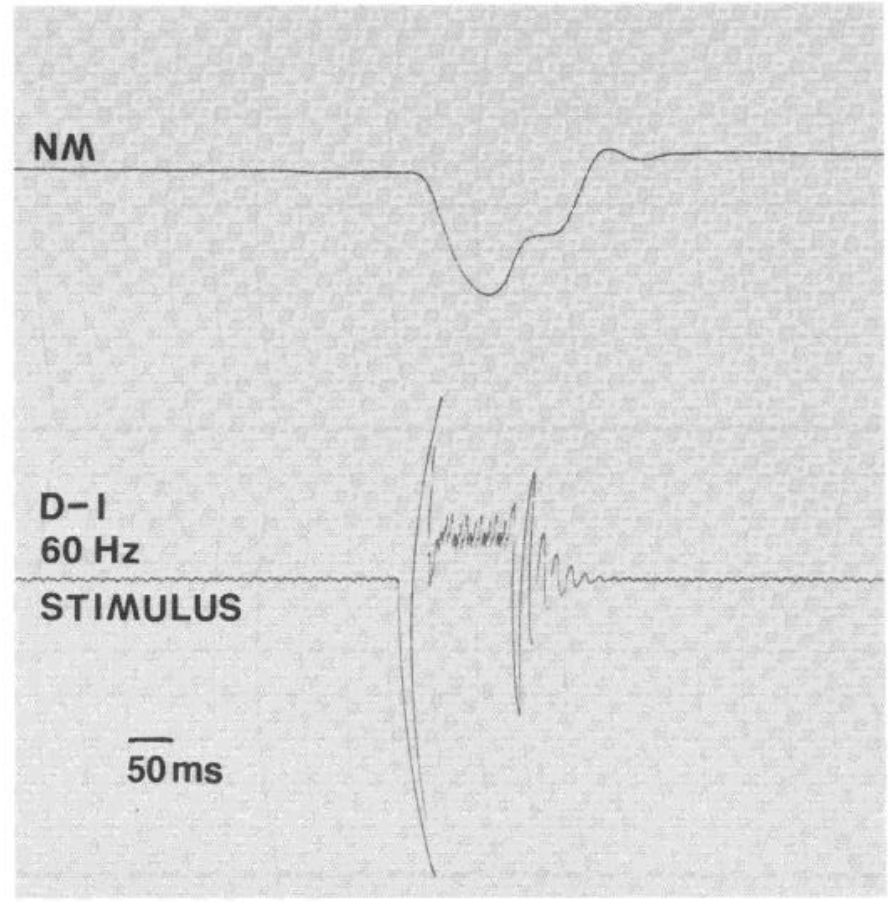

Figure 9. Example of $60-\mathrm{Hz}$ D-I stimulation-induced NM extension and eyelid closure. Stimulus was $60 \mathrm{~Hz} \mathrm{AC}, 150 \mathrm{msec}, 75 \mu \mathrm{A}$. Each division represents $0.5 \mathrm{~mm}$ of NM movement across the eyeball.

paramedian lobules and paraflocculus in one additional animal and the removal of the dorsal vermis in an additional four animals failed to replicate these effects. The differences may have been in differential degeneration of afferents to the deep cerebellar nuclei or to direct damage to some as yet unidentified afferents to the cerebellar deep nuclei which are critical for the production of the conditioned eyeblink response. Indeed, we have found that electrolytic white matter lesions of the dorsal aspect of the inferior cerebellar peduncle, ventral to the cerebellar cortex, dorsal and anterior to the D-I nuclei, can abolish the learned eyeblink response $(n=4)$.

Interestingly, lesions of the ansiform lobule or of both the ansiform and paramedian lobules could significantly alter the amplitude-time course of the conditioned response in some animals such that, although conditioned eyelid closure occurred with normal amplitude after the onset of the CS, the eyelids often reopened before the onset of the corneal airpuff. This maladaptive eyeblink response was not seen in any control animal or after removal of any other part of the cerebellar cortex. The ansiform, paramedian lobules and lobulus simplex project to the medial dentate and interpositus region of the deep nuclei (Jansen and Brodal, 1942; Goodman et al., 1963).

\section{Discussion}

The present study indicates that neurons in localized regions of the ansiform lobule, anterior lobe, lobule c, and a subregion of the D-I nuclei respond in relation to the performance of the learned eyeblink response.

The onset of the neuronal responses within the ansiform cortex often covaried significantly (up to values of 0.98 ) with the onset of the learned eyeblink response, suggesting that these responses were intimately related to the performance of the conditioned response. Since the ansiform lobule projects to the D-I nuclei, which appear to be critically involved in the production of the learned eyeblink response, the activity of this neuronal region probably also participates in the production of the learned response. Indeed, the cortical lesion data support this participation, since lesions of the ansiform lobule can change the amplitude-time course of the conditioned response, even though these lesions do not abolish the learned response. However, these lesion data must be interpreted with caution since in some animals it was noticed that restricted regions of the inferior olivary complex can undergo marked cell loss, which may change critical inputs to the D-I nuclei.

The average onset latency of the responses in the ansiform lobule was $29.3 \pm 16.5 \mathrm{msec}$ before the onset of the behavioral NM response. However, in this paradigm other facial movements are known to be involved with EMG activity in the eyelid musculature (musculus orbicularis oculi) occurring at the shortest latency $(29.5 \pm 8.2 \mathrm{msec}$ before the NM response). The fact that the granule cells of the ansiform (crus I) region of the cerebellar cortex receive a direct projection from neurons within the fifth sensory nuclei and respond well to light cutaneous stimulation of the upper face and large mystacial vibrissae with a latency of 3 to 5 msec (Carpenter and Hanna, 1961; Shambes et al., 1978a, b; Somana et al., 1980) indicates that the neuronal responses in the cerebellar cortex reported in the present study may contain significant somatosensory or proprioceptive feedback components from the production of the movement itself. Since the D-I nuclei may also receive a projection from the fifth sensory nuclei, this may also hold true for some of the neural activity within these nuclei (Chan-Palay, 1977). This feedback component would most likely contribute to the neural responses which occurred just before $(20 \mathrm{msec})$ or after the onset of the NM response.

Not all of the responses from the chronic or acute recordings can be explained in terms of sensory feedback. We found that in some cases the D-I neuronal activity consistently preceded the NM response by 40 to 60 msec. Perhaps more importantly, the pattern of neuronal activity within the D-I nuclei often was not closely associated with the amplitude-time course (i.e., "model") of the unconditioned eyeblink response but did appear associated with the performance of the learned eyeblink response (Figs. 5 and 6). Thach $(1970 \mathrm{a}, \mathrm{b}, 1975,1978)$ has reported that neurons in the D-I nuclei fire in relation to toneand/or light-signaled prompt arm-wrist movements in the monkey. The distribution of onset latencies for neurons in the dentate nucleus was found to precede the movement by approximately $90 \mathrm{msec}$ and preceded onset latency distributions of EMG and neurons located in the interpositus, anterior lobe, motor cortex (Burton and Onoda, 1977; Thach, 1970a, b, 1975, 1978; Takeuchi et al., 1979), and red nucleus (Otero, 1976). However, considerable overlap between all of these distributions was evident.

It has recently been reported that, in monkeys trained to perform an arm movement sequence in response to a visual or auditory signal, neurons of the dentate nucleus fire not only in relation to the occurrence of learned response but also in relation to the occurrence of the signaling stimulus. This response to the signal to move was found to extinguish as the animals' behavioral response extinguished when reward was withheld (Chapman et al., 1982).

Cooling of the dentate nucleus in monkeys trained to perform a prompt arm-wrist flexion task causes the execution of the task to be delayed by 90 to 250 msec (Brooks et al., 1973; Meyer-Lohmann et al., 1977; Brooks, 1979). Furthermore, cooling of the dentate in a monkey that has just learned a new variation of an arm-wrist task reverts the animal's learned arm movements back to prelearning levels of performance (Horvath et al., 1968).

Using classical conditioning, we have shown that lesions of the ipsilateral cerebellum, the D-I nuclei, or of the superior cerebellar peduncle abolish the conditioned eyeblink response but have no effect on the reflexive response or the ability of the animal to learn the response with the contralateral NM- 


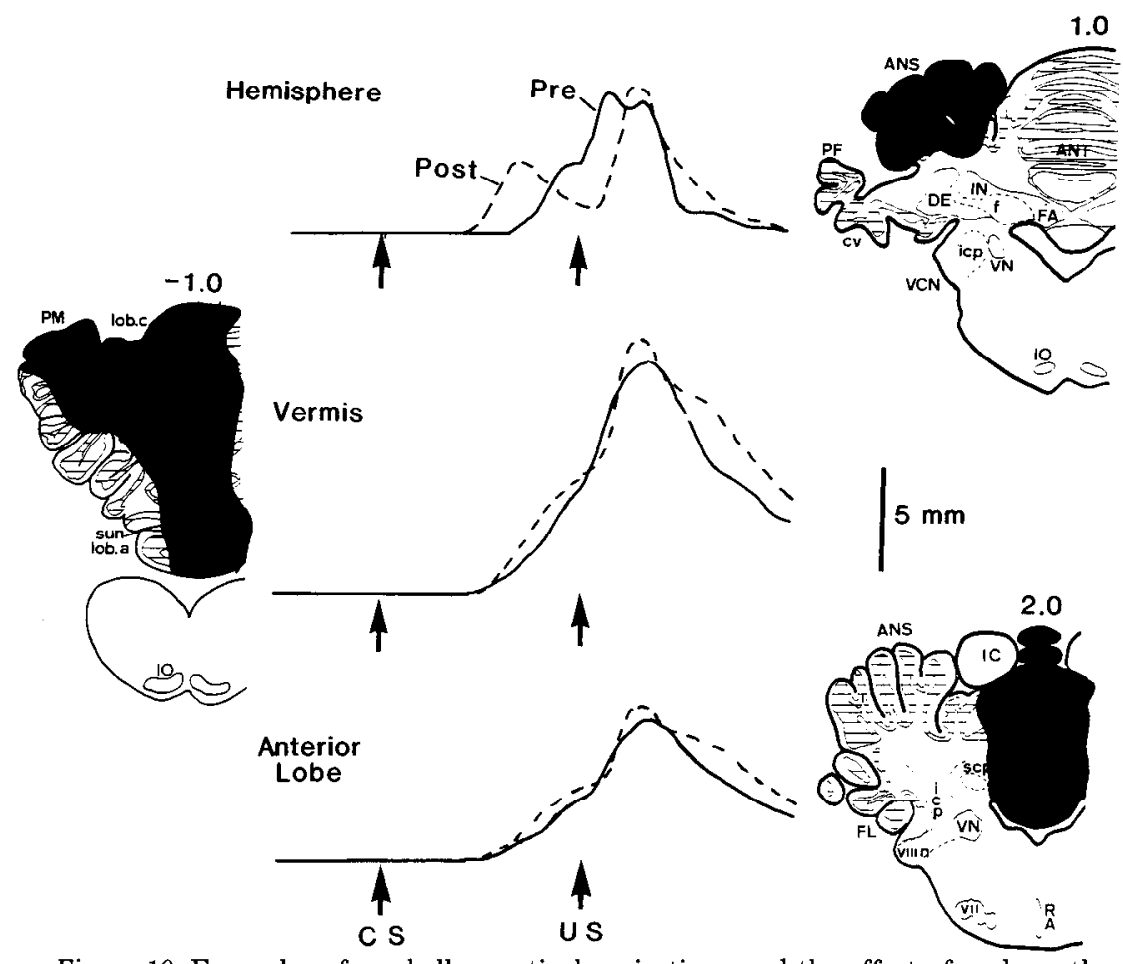

Figure 10. Examples of cerebellar cortical aspirations and the effect of such on the learned eyeblink response. The upper set of data is from an animal with removal of the ansiform lobule and the hemispherical portions of lobulus simplex. The reconstruction of the removed area on the right is through the broadest extent of the lesion. The solid trace illustrates the average NM response on the day before the lesion, and the dashed line represents the average NM response of all training after the lesion. Note the persistence of the conditioned response although, in this animal, the amplitude-time course of the response is altered. The middle set illustrates data from an animal in which the vermal lobes were removed, and the bottom set illustrates the data from an animal in which the anterior lobe was removed. In neither case was the amplitude-time course of the conditioned response significantly altered. $A N S$, ansiform lobule; $A N T$, anterior lobe; $c v$, ventral crus; $D E$, dentate nucleus; $f$, fibers; $F A$, fastigial nucleus; $F L$, flocculus; $I C$, inferior colliculus; icp, inferior cerebellar peduncle; $I N$, interpositus nucleus; $I O$, inferior olivary complex; $l o b$. $a$, lobule a; $l o b$. $c$, lobule $c ; P F$, paraflocculus; $P M$, paramedian lobule; $R A$, raphe; scp, superior cerebellar peduncle; sun, sulcus uvulonodulus; $V C N$, ventral cochlear nucleus; vii, seventh nucleus; viii $n$, nerve of the eighth nucleus; $V N$, vestibular nucleus.

eyelid (McCormick et al., 1981, 1982a, b; Clark et al., 1982, 1984).

Previous investigators have found in the dog that complete removal of the cerebellum abolishes or severely impairs previously learned classically conditioned leg flexion (Popov, 1929; Karamian et al., 1969) and salivary (Lifshitz, 1947; Krasusky, 1957) responses to a number of auditory and visual conditioning stimuli. Recently, Donegan et al. (1983) have shown that unilateral lesions of the lateral cerebellum that include the medial portion of the interpositus nucleus abolish the conditioned leg flexion response of the rabbit. These lesion studies therefore have shown that the cerebellum (particularly the D-I nuclei) is in some way critical to the production of classically conditioned responses.

The fact that stimulation in some locations of the D-I nuclei can elicit eyeblink responses indicates that these regions contain neural elements which when activated can ultimately excite motoneurons controlling the eyeblink response (Brogden and Gantt, 1942; Schultz et al., 1979; Rispal-Padel et al., 1982). The fact that superior cerebellar peduncle lesions abolish the ability of D-I stimulation to elicit eyeblinks implies that it is the activation of the projecting nuclei of these nuclei which causes the eyeblinks to be performed. Recent evidence indicates that the red nucleus may be an essential efferent pathway by which the D-I nuclei can control the production of learned eyeblink responses (Courville, 1966b, c; Desmond et al., 1983; Haley et al., 1983; Madden et al., 1983; Rosenfield and Moore, 1983).

It is interesting to note that the same lesion which eliminates the ability of the cerebellum to produce eyeblinks (superior cerebellar peduncle lesion) also eliminates the ability of the animal to perform learned eyeblinks (McCormick et al., 1982b).

We conclude that the critical region of the D-I nuclei is not only active during, and necessary for, but also is capable of producing, the classically conditioned eyeblink response. Thus, the medial dentate and/or interpositus region is an essential part of the neuronal circuitry involved in the production of the learned eyeblink response (i.e., the "learned response circuit").

Localization of the critical neuronal changes which represent the associative process (i.e., the "memory trace") for the learned eyeblink response to the D-I nuclei is at least a reasonable possibility. In terms of evoked increases in unit activity in the D-I region, auditory and somatosensory information are both present, a necessary requirement for the formation of associations. Detailed somatosensory information about the occurrence of movements, i.e., feedback, is also present and is a prominent feature of cerebellar input generally. Thus the D-I nuclei possess many of the basic requirements for the formation and storge of the associative changes, i.e., it receives input from all sensory modalities concerned (auditory, somatosensory, and 
proprioceptive) and possesses the ability to initiate and control the production of the learned eyeblink response. However, we do not yet have sufficient data to determine whether such an associative process does occur within the D-I nuclei. Collectively, our results to date suggest that the "memory trace" is either in the D-I nuclei or in afferent structures for which the cerebellum is a mandatory efferent, or both.

A number of investigators have suggested that the cerebellum is involved in the learning and, perhaps, storage of "motor programs" (Brindley, 1964; Ito, 1968, 1974, 1982; Marr, 1969; Albus, 1971; Gilbert, 1974; Eccles, 1977). All of these authors have suggested that the storage of such information would take place in the cerebellar cortex as a modulation of the parallel fiber synapses of the granule cells onto the Purkinje cells. Indeed, lesions of the cerebellar flocculus have been found to block plasticity of the vestibulo-ocular reflex (VOR) (Ito, 1974; Ito et al., 1980) and recovery of VOR symmetry after hemilabyrinthectomy (Courjon et al., 1982). Furthermore, recording results from the cerebellar flocculus in the rabbit during adaptive modification of the VOR support this hypothesis (Dufosse et al., 1978), although differing results have been reported in the monkey (Miles and Lisberger, 1981).

In our own experiments, we have failed to find any cortical region which, when removed, consistently abolished the conditioned eyelid response, even though all cortical regions except for the flocculus have been removed. The flocculus, itself, most probably is not the critical structure involved in the known effective lesions, since the lesions track the superior cerebellar peduncle through the brainstem and therefore do not involve the known projections of the flocculus (Anguate and Brodal, 1967; Dow, 1936). However, this is not to say that the cerebellar cortex is not critically involved in the normal production of the learned eyeblink response. Indecd, since robust neuronal responses occur within the ansiform cortex which are highly related to the performance of the conditioned response, and since lesions of the ansiform cortex can alter the amplitudetime course of the conditioned response, it would seem that this cortical region is involved in the performance of the learned response. It is possible that this cerebellar cortical region plays an important role in initial learning of the conditioned response. However, the cerebellar cortex does not appear to be essential for the memory of the conditioned eyeblink response.

\section{References}

Albus, J. S. (1971) A theory of cerebellar function. Math. Biosci. 10: $25-61$.

Alkon, D. L. (1980) Membrane depolarization accumulates during acquisition of an associative behavioral change. Science $210: 1375-$ 1376.

Anguate, P., and A. Brodal (1967) The projection of the "vestibulocerebellum" onto the vestibular nuclei in the cat. Arch. Ital. Biol. 105: 441-479.

Berger, T. W., and R. F. Thompson (1978) Neuronal plasticity in the limbic system during classical conditioning of the rabbit nictitating membrane response. I. The hippocampus. Brain Res. 145: 323-346.

Brakel, S., T. Babb, J. Mahnke, and M. Verzeano (1971) A compact amplifier for extracellular recording. Physiol. Behav. 6: 731-733.

Brindley, G. S. (1964) The use made by the cerebellum of the information that it receives from sense organs. Int. Brain Res. Org. Bull 3: 30 .

Brodal, A. (1940) The cerebellum of the rabbit: A topographical atlas of the folia as revealed in transverse sections. J. Comp. Neurol. 72: $63-81$.

Brodal, A. (1981) Neurological Anatomy in Relation to Clinical Medicine, Oxford University Press, Oxford.

Brogden, W. J., and W. H. Gantt (1942) Interneural conditioning: Cerehellar conditioned reflexes. Arch. Neurol. Psychiatr. 48: 437455 .

Bromiley, R. B. (1948) Conditioned responses in a dog after removal of neocortex. J. Comp. Physiol. Psychol. 11: 102-110.
Brooks, V. B. (1979) Control of intended limb movements by the lateral and intermediate cerebellum. In Integration in the Nervous System, D. P. C. Lloyd and V. D. Wilson, eds., pp. 321-356, Igaku-Shoin Ltd., Tokyo.

Brooks, V. B., I. B. Kozlovskaya, A. Atkin, F. E. Horvath, and M. Uno (1973) Effects of cooling the dentate nucleus on tracking-task performance in monkeys. J. Neurophysiol. 36: 974-995.

Burton, J. E., and N. Onoda (1977) Interpositus neuron discharge in relation to voluntary movement. Brain Res. 121: 167-172.

Carpenter, M. B., and G. R. Hanna (1961) Fiber projections from the spinal trigeminal nucleus in the cat. J. Comp. Neurol. 117: 117-131.

Cegavske, C. F., R. F. Thompson, M. M. Patterson, and I. Gormezano (1976) Mechanisms of efferent control of the reflex nictitating membrane response in rabbit (Oryctolagus cuniculus). J. Comp. Physiol. Psychol. 90: 411-423.

Chan-Palay, V. (1977) Cerebellar Dentate Nucleus. Organization, Cytology and Transmitters, Springer-Verlag, New York.

Chapman, C. E., G. Spidalieri, and Y. Lamarre (1982) A study of sensorimotor properties of dentate neurons during conditioned arm movements in the monkey. Soc. Neurosci. Abstr. 8: 830 .

Clark, G. A., D. A. McCormick, D. G. Lavond, K. Baxter, W. J. Gray, and R. F. Thompson (1982) Effects of electrolytic lesions of cerebellar nuclei on conditioned behavioral and hippocampal neuronal responses. Soc. Neurosci. Abstr. 8: 22.

Clark, G. A., D. A. McCormick, D. G. Lavond, and R. F. Thompson (1984) Effects of lesions of cerebellar nuclei on conditioned behavioral and hippocampal responses. Brain Res. 291: 125-136.

Cohen, D. H. (1980) The functional neuroanatomy of a conditioned response. In Neural Mechanisms of Goal-Directed Behavior and Learning, R. F. Thompson, L. H. Hicks, and B. V. Shrykov, eds., pp. 283-302, Academic Press, Inc., New York.

Courjon, J. H., J. M. Flandrin, M. Jeannerod, and R. Schmid (1982) The role of the flocculus in vestibular compensation after hemilabyrinthectomy. Brain Res. 239: 251-257.

Courville, J. (1966a) The nucleus of the facial nerve: The relation between cellular groups and peripheral branches of the nerve. Brain Res. 1: 338-354.

Courville, J. (1966b) Rubrobulbar fibers to the facial nucleus and the lateral reticular nucleus (nucleus of the lateral funiculus). An experimental study in the cat with silver impregnation methods. Brain Res. 1: 317-337.

Courville, J. (1966c) Somatotopical organization of the projection from the nucleus interpositus anterior of the cerebellum to the red nucleus: An experimental study in the cat with silver impregnation methods. Exp. Brain Res. 2: 191-215.

Desmond, J. E., M. E. Rosenfield, and J. M. Moore (1983) Red nucleus and supratrigeminal reticular formation: Brain stem components of the classically conditioned nictitating membrane response. Soc. Neurosci. Abstr. 9: 331 .

Donegan, N. H., R. W. Lowery, and R. F. Thompson (1983) Effects of lesioning cerebellar nuclei on conditioned leg-flexion responses. Soc. Neurosci. Abstr. 9: 331.

Dow, R. S. (1936) Fiber connections of the posterior parts of the cerebellum in the cat and rat. J. Comp. Neurol. 63: 527-548.

Dufosse, M., M. Ito, P. J. Jastreboff, and Y. Miyashita (1978) A neuronal correlate in rabbit's cerebellum to adaptive modification of the vestibulo-ocular reflex. Brain Res. 150: 611-616.

Eccles, J. C. (1977) An instruction-selection theory of learning in the cerebellar cortex. Brain Res. 127: 327-352.

Fadiga, E., and G. C. Pupilli (1964) Teleceptive components of the cerebellar function. Physiol. Rev. 44: 432-486.

Gilbert, P. F. C. (1974) A theory of memory that explains the function and structure of the cerebellum. Brain Res. 70: 1-18.

Girden, E., F. A. Mettler, G. Finch, and E. Culler (1936) Conditioned responses in a decorticate dog to acoustic, thermal, and tactile stimulation. J. Comp. Psychol. 21: 367-385.

Goodman, D. C., R. E. Hallet, and R. B. Welch (1963) Patterns of localization in the cerebellar cortico-nuclear projections of the albino rat. J. Comp. Neurol. 121: 51-67.

Gray, T. S., S. E. McMaster, J. A. Harvey, and I. Gormezano (1981) Localization of retractor bulbi motoneurons in the rabbit. Brain Res. 226: 93-106.

Haley, D. A., D. G. Lavond, and R. F. Thompson (1983) Effects of contralateral red nucleus lesions on retention of the classically conditioned nictitating membrane/eyelid response. Soc. Neurosci. Abstr. 9: 643 . 
Horvath, F. E., A. Atkin, I. Kozlovskaya, D. R. G. Fuller, and V. B. Brooks (1968) Effects of cooling the dentate nucleus on alternating bar-pressing performance in monkey. Int. J. Neurol. 7: 252-270.

Ito, M. (1968) Neurophysiological aspects of the cerebellar motor control system. Int. J. Neurol. 7: 162-176.

Ito, M. (1974) The control mechanisms of cerebellar motor systems. In The Neurosciences: Third Study Program, F. O. Schmitt and F. G. Worden, eds., pp. 293-303, MIT Press, Boston.

Ito, M. (1982) Cerebellar control of the vestibulo-ocular reflex-around the flocculus hypothesis. Annu. Rev. Neurosci. 5: 275-296.

Ito, M., P. J. Jastreboff, and Y. Miyashita (1980) Retrograde influence of surgical and chemical flocculectomy upon dorsal cap neurons of the inferior olive. Neurosci. Lett. 20: 45-48.

Jansen, J., and A. Brodal (1942) Experimental studies on the intrinsic fibers of the cerebellum. III. The cortical nuclear projection in the rabbit and monkey (Macacus Rhesus). Skr. Nor. Vidensk.-Akad. Oslo I. Mat. Naturvidensk. Kl. 3: 1-50.

Kandel, E. R., and J. H. Schwartz (1982) Molecular biology of learning: Modulation of transmitter release. Science 218: 433-443.

Kapp, B. S., R. C. Frysinger, M. Gallagher, and J. R. Hazelton (1979) Amygdala central nucleus lesions: Effect on heart rate conditioning in the rabbit. Physiol. Behav. 23: 1109-1117.

Karamian, A. I., V. V. Fanardijian, and A. A. Kosareva (1969) The functional and morphological evolution of the cerebellum and its role in behavior. In Neurobiology of Cerebellar Evolution and Development, First International Symposium, R. Llinas, ed., pp. 639-673, American Medical Association, Chicago.

Krasusky, V. K. (1957) General nature of changes of food conditioned reflexes in dogs following a surgical lesion of the cerebellum. $\mathrm{Zh}$. Vyssh. Nerv. Deiat. 7: 733-740.

Lavond, D. G., D. A. McCormick, G. A. Clark, D. T. Holmes, and R. F. Thompson (1981) Effects of ipsilateral rostral pontine reticular lesions on retention of classically conditioned nictitating membrane and eyelid response. Physiol. Psychol. 9: 335-339.

Lebedinskaia, S. I., and J. S. Rosenthal (1935) Reactions of a dog after removal of the cerebral hemispheres. Brain 58: 412-419.

Lifshitz, N. N. (1947) Influence of the cerebellar ablation on conditioned reflexes in dogs. Trudy Fiziol. Inst. Pavlova Acad. Sci. (Moscow) 2: 11-50.

Lincoln, J. S., D. A. McCormick, and R. F. Thompson (1982) Ipsilateral cerebellar lesions prevent learning of the classically conditioned nictitating membrane/eyelid response. Brain Res. 242: 190-193.

Madden, J., IV, D. A. Haley, J. D. Barchas, and R. F. Thompson (1983) Microinfusion of picrotoxin into the caudal red nucleus selectively abolishes the classically conditioned nictitating membrane/eyelid response in the rabbit. Soc. Neurosci. Abstr. 9: 830.

Mamounas, L. A., J. Madden, IV, J. D. Barchas, and R. F. Thompson (1983) Microinfusion of GABA antagonists into the cerebellar deep nuclei selectively abolishes the classically conditioned eyelid response in the rabbit. Soc. Neurosci. Abstr. 9: 830.

Marek, G. J., S. E. McMaster, I. Gormezano, and J. A. Harvey (1984) The role of the accessory abducens nucleus in the rabbit nictitating membrane response. Brain Res. 229: 215-229.

Marr, D. (1969) A theory of cerebellar cortex. J. Physiol. (Lond.) 202. 437-470.

McCormick, D. A., and R. F. Thompson (1984) Cerebellum: Essential involvement in the classically conditioned eyelid response. Science 223: 296-299.

McCormick, D. A., D. G. Lavond, G. A. Clark, R. E. Kettner, C. E. Rising, and R. F. Thompson (1981) The engram found? Role of the cerebellum in classical conditioning of nictitating membrane and eyelid response. Bull. Psychon. Soc. 18: 103-105.

McCormick, D. A., G. A. Clark, D. G. Lavond, and R. F. Thompson (1982a) Initial localization of the memory trace for a basic form of learning. Proc. Natl. Acad. Sci. U. S. A. 79: 2731-2735.

McCormick, D. A., P. E. Guyer, and R. F. Thompson (1982b) Superior cerebellar peduncle lesions selectively abolish the ipsilateral classically conditioned nictating membrane/eyelid response of the rabbit. Brain Res. 244: 347-350.

McCormick, D. A., D. G. Lavond, and R. F. Thompson (1982c) Concomitant classical conditioning of the rabbit nictitating membrane and eyelid responses: Correlations and implications. Physiol. Behav. 28: $769-775$.

McCormick, D. A., D. G. Lavond, and R. F. Thompson (1983) Neuronal responses of the rabbit brainstem during performance of the classically conditioned nictitating membrane/cyeblink response in the rabbit. Brain Res. 271: 73-88.
Meyer-Lohmann, J., J. Hore, and V. B. Brooks (1977) Cerebellar participation in generation of prompt arm movements. J. Neurophysiol. 40: 1038-1050.

Miles, F. A., and S. G. Lisberger (1981) Plasticity in the vestibuloocular reflex: A new hypothesis. Annu. Rev. Neurosci. 4: 273-299.

Mortimer, J. A. (1973) Temporal sequence of cerebellar Purkinje and nuclear activity in relation to acoustic startle response. Brain Res. $50: 457-462$.

Mortimer, J. A. (1975) Cerebellar responses to teleceptive stimuli in alert monkeys. Brain Res. 83: 369-390.

Norman, R. J., J. R. Villablanca, K. A. Brown, J. A. Schwafel, and J. S. Buckwald (1974) Classical eyeblink conditioning in the bilaterally hemispherectomized cat. Exp. Neurol. 44: 363-380.

Oakley, D. A., and I. S. Russell (1977) Subcortical storage of Pavlovian conditioning in the rabbit. Physiol. Behav. 18: 931-937.

Otero, J. B. (1976) Comparison between red nucleus and precentral neurons during learned movements in the monkey. Brain Res. 101: $37-46$.

Pavlov, I. P. (1927) Conditioned Reflexes: An Investigation of the Physiological Activity of the Cerebral Cortex, G. V. Anrep, transl./ed., Oxford University Press, Oxford.

Popov, N. F. (1929) The role of the cerebellum in elaborating the motor conditioned reflexes. In Higher Nervous Activity, D. S. Fursikov, M. O. Gurevich, and A. N. Zalmanzon, eds., Vol. 1, pp. 140-148, Com. Acad. Press, Moscow.

Rispal-Padel, L., F. Circirata, and C. Pons (1982) Cerebellar nuclear topography of simple and synergistic movements in the alert baboon (Papio papio). Exp. Rrain Res. 47: 365-380.

Rosenfield, M. E., and J. W. Moore (1983) Red nucleus lesions disrupt the classically conditioned nictitating membrane response in rabbits. Behav. Brain Res. 10: 393-398.

Schneiderman, N., D. H. Van Dercar, A. L. Yehle, A. A. Manning, and T. Golden (1969) Vagal compensatory adjustment: Relationship to heart rate classical conditioning in rabbits. J. Comp. Physiol. Psychol. 68: 175-183.

Schultz, W., E. B. Montgomery, Jr., and R. Marini (1979) Proximal limb movements in response to microstimulation of primate dentate and interpositus nuclei mediated by brain-stem structures. Brain 102: $127-146$

Shambes, G. M., J. M. Gibson, and W. Welker (1978a) Fractured somatotopy in granule cell tactile areas of rat cerebellar hemispheres revealed by micromapping. Brain Behav. Evol. 15: 94-140.

Shambes, G. M., D. H. Beerman, and W. Welker (1978b) Multiple tactile areas in cerebellar cortex: Another patchy cutaneous projection to granule cell columns in rats. Brain Res. 157: 123-128.

Snider, R. S., and A. Stowell (1944) Receiving areas of tactile, auditory, and visual systems in the cerebellum. J. Neurophysiol. 7: 331-357.

Somana, R., N. Kotchabhakdi, and F. Walberg (1980) Cerebellar afferents from the trigeminal sensory nuclei in the cat. Exp. Brain Res. 38: $57-64$

Takeuchi, Y., K. Nakano, M. Uemura, K. Matsuda, R. Matsushima, and N. Mizuno (1979) Mesencephalic and pontine afferent fiber system to the facial nucleus in the cat. A study using horseradish peroxidase and silver impregnation techniques. Exp. Neurol. 66: 330 342.

Thach, W. T. (1970a) Discharge of cerebellar neurons related to two maintained postures and two prompt movements. I. Nuclear cell output. J. Neurophysiol. 33: 527-536.

Thach, W. T. (1970b) Discharge of cerebellar neurons related to two maintained postures and two prompt movements. II. Purkinje cell output and input. J. Neurophysiol. 33: 537-547.

Thach, W. T. (1975) Timing of activity in cerebellar dentate nucleus and cerebral motor cortex during prompt volitional movement. Brain Res. 88: 233-241.

Thach, W. T. (1978) Correlation of neural discharge with patlern of force of muscular activity, joint position, and direction of next intended movement in motor cortex and cerebellum. J. Neurophysiol. 41: 654-676.

Thompson, R. F., T. W. Berger, T. F. Cegavske, M. M. Patterson, R. A. Roemer, T. A. Teyler, and R. A. Young (1976) The search for the engram. Am. Psychol. 31: 209-227.

Tsukahara, N., Y. Oda, and T. Notsu (1981) Classical conditioning mediated hy the red nucleus in the cat. J. Neurosci. 1: 72-79.

Woody, C. D., and J. Engle, Jr. (1972) Changes in unit activity and thresholds to electrical microstimulation at coronal-pericruciate cortex of cat with classical conditioning of different facial movements. J. Neurophysiol. 35: 230-241. 